\title{
Conferencia de Seguridad, Munich 2007: ¿Cuál es la inseguridad?
}

\author{
Francisco JaVier IBISATE
}

Departamento de Economía UCA, San Salvador

RESUMEN: En este artículo, escrito pocas semanas antes de su fallecimiento, el padre lbisate, como era su costumbre, pasa revista a las cumbres mundiales, en este caso, la Conferencia de Seguridad celebrada en Munich. En él, constata la grave contradicción de una Conferencia de Seguridad en la que participan los gobiernos más involucrados en guerras y agresiones a escala mundial, esto es, los que vuelven al mundo un lugar más inseguro. En vez de confundir seguridad con armamentismo y guerra, plantea Ibisate, es más racional construir la seguridad mundial asegurando una vida digna para todos los pueblos del mundo.

ABSTRACT: In this essay, written a few weeks before his demise, father Ibisate, as he used, reviews the world summits, in this case, the Conference on Security in Munich. The author states the outrageous contradiction of a Conference on Security in which the governments that make the world unsafe are the guests. Instead of confusing security with warfare, poses Ibisate, it is more rational to build world security ensuring a worthy life for all the people in the world. 


\section{El menú de los invitados}

$\mathrm{A}^{\mathrm{l}}$ I leer el anuncio de la XLIII Conferencia de Seguridad en Munich el 9 de febrero de 2007, con la participación de unas 250 personalidades de cuarenta países diferentes, me confirmé en la idea de que el problema número uno del mundo es la inseguridad. Se trata de la XLIII Conferencia de Seguridad, lo cual significa que la inseguridad tiene una larga historia; con razón el pasado mes de enero reflexionábamos sobre el cuadragésimo mensaje papal de la Jornada Mundial de la Paz. La inseguridad viene de lejos, pero ¿cuál es la inseguridad que estará en el centro de la atención, de la preocupación y del propósito de enmienda de la presente conferencia? La pregunta tiene una razón de ser, porque las grandes potencias han arrinconado el primer "objetivo del milenio", la paz, la seguridad y el desarme.

$\mathrm{Al}$ ir armando el mosaico de las inseguridades que los señores de la guerra atizan en lo que fuera el patio trasero de la URSS y en el Próximo y Medio Oriente, llego a la conclusión de que se reavivan las cenizas de la guerra fría y se deja en la vía muerta los reclamados objetivos del milenio. En el reciente foro social de Nairobi e incluso en el foro económico de Davos, se hizo memoria con algo de preocupación mundial de los objetivos del milenio. Sin embargo, los abiertos enfrentamientos en la presente Conferencia de Se- guridad muestran que reviven los recelos militares de la guerra fría, la prioridad a las políticas de la guerra sin fin y la búsqueda de enemigos que justifiquen la carrera armamentística. La conclusión es triste: la inseguridad militar de unas pocas potencias relega al largo plazo la seguridad humana, social y económica de la mayoría de países del tercer mundo. Me refiero en concreto al desarrollo y erradicación de la pobreza; a la protección de nuestro medio ambiente; a los derechos humanos, democracia y buen gobierno; a la protección de las personas vulnerables. La única justificación para hablar de la seguridad asentada en la "guerra sin fin" es que con ella se deja en la vía muerta la Declaración del Milenio y reinventamos una "nueva guerra fría".

Para conocer el género de inseguridad que se discutirá en Munich, consulté el menú de los invitados. Tzipi Livni, ministra de Asuntos Exteriores de Israel pronunciará el tradicional discurso de apertura. Pregunta: ¡es ella la persona más adecuada para inaugurar una conferencia de seguridad? ¿Cuál seguridad?. A modo de contraste, otro participante será Fuad Siniora, primer ministro libanés. ¿Hablarán de la misma seguridad? Angela Merkel, Canciller de Alemania, pronunciará su primer discurso en calidad de presidenta del Consejo Europeo y del G-8. Anuncia dos insegurida- 
des: la amenaza mundial del cambio climático, donde todos están de acuerdo pero sin ratificar acuerdos. La segunda inseguridad gira en torno a Irán, Irak, Afganistán y Oriente Medio. En esta amplia zona ¿quién o quiénes encendieron la mecha de la inseguridad? El G-8 y el Consejo Europeo ihan sido justos y equitativos al negar su ayuda económica al actual gobierno palestino, democráticamente elegido? En ciertos aspectos ino han sido marionetas de la Casa Blanca? Así lo afirman algunos de sus acreditados internacionalistas.

Pero el menú más inquietante integra cuatro o cinco personajes. Vladimir Putin, acompañado de su ministro de Defensa, Sergei Ivanov, acusan vigorosamente el levantamiento de bases militares norteamericanas en Polonia y República Checa, acusando a la OTAN de extender su presencia militar en zonas que fueron el patio trasero de la URSS. Es decir, hablan en nombre de un imperio, que todavía cuenta con el arma del petróleo y de miles de ojivas nucleares. En este diálogo participan representantes de otro imperio. El nuevo ministro de Defensa y presidente del Pentágono, Robert Gates, el Secretario General de OTAN, Jaap de Hopo Echefler, John McCain, aspirante a la presidencia de EE.UU., y tal vez Javier Solana se porte bien con Irán.

Si se tratara simplemente de bruscas exclamaciones que se digieren en los banquetes de trabajo no sería mayor el problema. Pero la verdad es que sigue la invasión y la humillación en Palestina y la amenaza de una guerra civil en el Líbano. Todos menos uno estamos de acuerdo en que la invasión de Irak ha sido el mayor insulto al "derecho de la humanidad", pero existe el peligro real de que se bombardeen las centrales nucleares de Irán para justificar la invasión de Irak y para dar seguridad a Israel.

Hay otro problema y ojalá otra posible lección. El imperio soviético se hundió por su propio peso $y$ al descomponerse la URSS, Rusia está viviendo la humillación de ser una potencia obligada a demandar ingentes préstamos del FMl, que se han traducido en una elevada deuda externa. La clase militar siente en lo más hondo la humillación porque sus ojivas nucleares no son amenaza para las otras catorce repúblicas independientes, y los antiguos satélites buscan su seguridad bajo el paraguas de la OTAN. La recesión derivó en auténtico caos económico $y$ "nuevos zares multimillonarios" surgieron con la "desvergonzada privatización" de enormes empresas públicas. Vladimir Putin hizo demasiadas concesiones económicas y políticas a G. W. Bush con su generoso pacto petrolero y la firma de la Declaración de Roma; una serie de alianzas flexibles donde la Casa Blanca se llevó la mejor parte y Bush no le ha correspondido. Luego de la masacre del 3 de septiembre 2004 en la escuela de Beslan, V. Putin y G. W. Bush firman el pacto de la "guerra sin fin", guerra perdida de 


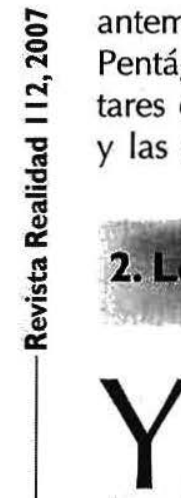

antemano. En estos últimos años el Pentágono siembra unas bases militares en fronteras cercanas a Rusia, y las acusaciones suenan a "nueva

\section{Los invitados} ahoo Noticias nos dice que está previsto que asistan 250 personalidades de cuarenta países a la Conferencia de Seguridad. Tzipi Livni pronunciará el tradicional discurso de apertura $y$ es de esperar que no destile misericordia y compasión para con sus coterráneos palestinos y libaneses. ¿Quiénes son y de dónde vienen Tpizi Livni y Ehud Olmert?. El periodista Johan Harl afirma que "Israel debe recordar su origen terrorista. EI grupo se llamaba Irgun y estaba formado por nacionalistas judíos cuyos hijos ahora forman parte de la elite gubernamental israelí. Durante las décadas 1930 y 1940, plantó bombas por toda Palestina, tomando como blancos tanto soldados británicos como a civiles palestinos. Tenía dos objetivos: expulsar a los imperialistas británicos y orillar mediante el terror a la población palestina a aceptar incondicionalmente la creación de Israel. Es dudoso que Ehud Olmert, el primer ministro israelí que ha declarado la 'guerra al terror', llegara a condenar al Irgun. Pasó tres años de su vida en sus campos de adiestramiento, mientras sus padres contrabandeaban armas para la organización. Tzipi Livni, la guerra fría". Es esto lo que me ha llevado a recordar historias pasadas que pueden inflar la burbuja de la inseguridad mundial. ministra de exterior, a quien muchos consideran la próxima primera ministra, es hija del director de operaciones militares del Irgun y orquestador de matanzas de civiles". ("La lucha palestina, silencio y complicidad internacional". ECA 2006; p. 745) Siendo el Próximo Oriente un tema central, es previsible por donde T. Livni enfilará sus tiros.

Los primeros oradores del programa son Angela Merkel y Vladimir Putin. Punto interesante es que A. Merkel pida hacer frente a "la gran amenaza de los próximos años, la del cambio climático. Estamos ante una amenaza global que requiere una respuesta global, porque nadie podrá escapar a ella". Reconoció que la Unión Europea es responsable del $15 \%$ de las emisiones de dióxido de carbono $\left(\mathrm{CO}_{2}\right)$, muy por detrás de Estados Unidos, pero hasta ahora, más comprometida con la protección del medioambiente. Dato importante porque la degradación medioambiental, que ha llegado a límites irreversibles, ha sido uno de los temas más preocupantes en el foro económico de Davos, el cual fue celebrado en enero de 2007.

También dijo que convenía hablar con una sola voz de asuntos 
que igualmente constituyen "una amenaza" para la paz y la estabilidad, como Irán y Medio Oriente. Respecto a Irán, Merkel afirmó que "la pelota está en el campo de Teherán", y recordó a sus autoridades que la comunidad internacional no aceptará trucos, sino una cooperación basada en la transparencia y la confianza mutua. En esos días terminaba el plazo de dos meses impuesto por Naciones Unidas al gobierno de Irán para poner fin a su proceso de enriquecimiento de uranio. Tema delicado, que incluso puede terminar en un bombardeo de sus centrales nucleares, dada la presión del vicepresidente Cheney y otros personeros de la Administración Bush.

Angela Merkel y Vladimir Putin serán los primeros oradores. El 31 de diciembre de 1999, Boris Yeltsin presenta su renuncia como presidente de Rusia y transfiere todos sus poderes a Putin, primer ministro. "Vladimir Putin, presidente interino, promete un Estado fuerte $y$ un nuevo patriotismo ruso". (Le Monde, $1^{\circ}$ de enero de 2000) ¿Quién es V. Putin? V. Putin viene de la KGB (la policía secreta soviética) y, originario de San Petersburgo, su oficina está presidida por el retrato del zar Pedro El Grande, que ensanchó las fronteras del imperio ruso y "para ello no dudó en decapitar a la tercera parte de la población". El pueblo ruso "sueña con la imagen de una nación que se haga respetar y ven en Pedro el Grande el hombre modelo que ellos buscan con sus votos". Desde la caída del muro de Berlín, el pueblo ruso $y$, sobre todo, su poderosa fuerza armada han sufrido un profundo deterioro y sienten que no les sirve para nada el haber acumulado armas nucleares capaces de aniquilar el planeta. Más aún, han tenido que tolerar que países otrora satélites se cobjjen bajo el paraguas de la OTAN y que la misma OTAN bombardee a antiguos aliados serbios (guerra de Serbia-Kosovo, 1998). El nacionalismo ruso se opone radicalmente a la secesión de la república chechena, justificando la guerra contra estos "terroristas", y la Duma (cámara baja) se opone a la reducción de las armas nucleares. Uno de los primeros actos de Putin será confirmar y visitar el frente de guerra de Chechenia, lo que le granjea el apoyo de la población". ("Rusia, la cólera de un pueblo humillado". Le Monde, 3 de enero de 2000)

Además, Putin firmará un decreto donde "Rusia aumenta sus posibilidades de uso defensivo de armas nucleares". Las circunstancias en que esa amenaza se haría realidad serían: "Si se produce una agresión contra Rusia o sus aliados y cuando no haya otros medios de evitar la liquidación de Rusia como elemento de las relaciones internacionales". El tono del documento es agresivo hacia Occidente al señalar claros puntos de confrontación, como "la disminución del papel internacional de Rusia, la expansión de la OTAN, las operaciones más allá de las fronteras de los países miembros 
y la posible instalación de bases de la Alianza cerca de Rusia". También se defiende un mundo multipolar en contraposición con el intento estadounidense de convertirse en la única superpotencia. (El País, 15 de enero de 2000)

Siete años más tarde Vladimir Putin lanza duras críticas contra Estados Unidos por llevar a cabo acciones "unilaterales" y contra la OTAN por su ampliación al Este de Europa. Criticó lo que calificó de "peligrosos" intentos de Estados Unidos de hacer un "mundo unipolar" mediante acciones unilaterales al margen de la legalidad internacional. Más en concreto se refiere a las operaciones más allá de los países miembros y a la instalación de bases de la Alianza cerca de Rusia. "Nadie me ha explicado ante qué amenaza se prepara la OTAN con ese despliegue ante nuestras fronteras", recordando que la OTAN no es una "organización universal"; "esa actuación de la OTAN no refuerza el nivel de confianza mutua". ("EE. UU. sorprendido $y$ decepcionado por las acusaciones lanzadas por Putin en Munich". El Mundo.es, 10 de febrero de 2007)

V. Putin deberá batirse en duelo verbal con el secretario estadounidense de Defensa, Robert Gates, antiguo presidente de la $\mathrm{ClA}$ y experto en la diplomacia de las cañoneras. Tienen en común que crecieron en el mundo del espionaje. Entre otros méritos, aviones de la CIA han realizado durante cuatro años vuelos clandestinos sobre ae- ropuertos europeos para capturar a sospechosos de pertenecer a la red Al Qaeda y hacer "entregas" a terceros países, para ser "juzgados". Sin duda se hablará de las nuevas bases militares de EE.UU. en Polonia y República Checa. El ministro de Defensa ruso, Sergei Ivanov, calificó como "muy poco amistosos" los planes de Washington de extender al Este de Europa su escudo antimisiles. El secretario general de la OTAN, Jaap de Hoop Scheffer, declaró después del discurso de Putin sentirse muy decepcionado y lamentó que el presidente ruso tenga una imagen tan errónea de la organización. "Nadie debería sentirse tan amenazado por la proximidad a sus fronteras del multilateralismo y la democracia". Ni Yugoslavia, ni Afganistán eran territorios confiados al paraguas de la OTAN. ¿Es esa la democracia militar?

En 1998 la OTAN, liderada por EE.UU., inicia la "guerra humanitaria" de Serbia y Kosovo sin autorización del Consejo de Seguridad de Naciones Unidas y lanza bombas de uranio empobrecido cuyos efectos destructivos en el entorno $y$ en las personas eran bien conocidos desde la guerra contra lrak en 1990. Repiten similar hazaña en octubre de 2001 con la invasión de Afganistán. Llama la atención que durante cuatro años la OTAN guardara un inaudito silencio sobre los vuelos clandestinos de la CIA en aeropuertos europeos. Uno de los puntos de la conferencia de Munich es solicitar a los gobiernos 
europeos el envío de más tropas al servicio de la OTAN, para controlar a los bélicos talibanes, que, entre paréntesis, no pertenecían al gremio Al Qaeda. A. Merkel habló del papel de la OTAN en la seguridad mundial, tesis no compartida por S. Ivanov, quien a su vez, es criticado por el senador republicano, John McCain, quien acusa a Rusia de querer mantener "su influencia imperialista en los Estados vecinos". Flotan duras acusaciones entre representantes de ambos imperios, que años antes habían pactado una alianza flexible.

Como actores de otros puntos de agenda, están presentes Javier Solana, en representación de la Unión Europea, el primer ministro libanés, Fuad Siniora, cuyo país peligra deslizarse en una guerra civil luego de la ofensiva israelí. Está presente Ali Lariyani, delegado de Irán ante la Agencia Internacional de energía Atómica (AIEA) en las presentes discusiones sobre el cumplimiento de las sanciones impues- tas por el Consejo de Seguridad de la ONU. Lariyani está demostrando verdaderas dotes de diplomático de línea pacífica, en este caso, defendiendo la legitimidad del enriquecimiento de uranio, con fines civiles, por parte de gobiernos que hayan firmado el Tratado de No Proliferación Nuclear. Batalla delicada porque los gobiernos de Israel y Estados Unidos, que ni firman ni se amarran a ningún tratado, desean llevar la serie de sanciones económicas, diplomáticas, financieras y comerciales hasta la amenaza de ataque militar. Bush y Condoleeza Rice repiten los mismos discursos de febrero $y$ marzo de 2003. ("Vientos fríos en Conferencia de Seguridad de Munich", Deutsche Welle: 12 de febrero de 2007) Estos son algunos de los más reconocidos participantes, artífices más bien de guerras y que ahora se baten en duelo para que del huevo de la guerra nazca la paloma de paz. Ojalá que la biotecnología estuviera tan adelantada.

\section{3. "Crisis global, responsabilidad global"}

- ste es el lema de la presente conferencia; en teoría todos estamos de acuerdo, pero en los debates internacionales aceptamos sólo el $50 \%$ del lema: la crisis es global, pero no todos los personajes arriba presentados se hacen partícipes de la responsabilidad global. También hay una pérdida de la memoria histórica. $\mathrm{Al}$ gobierno ruso le cuesta recordar lo que fue su imperio soviético y a la superpotencia norteamericana le cuesta mirar lo que puede ser su futuro próximo. Los imperios suben $y$ bajan y uno de los efectos más desagradables es que crean odios. G. W. Bush está logrando que más pueblos y naciones teman su imperio y que menos gentes de buena voluntad crean en 
él y pongan en él su confianza. A los líderes norteamericanos les puede ayudar recordar brevemente el hundimiento soviético.

Vladimir Putin, que hoy protesta por la instalación de bases militares norteamericanas al interior de Polonia y República Checa, antiguos satélites de la URSS, debe recordar que fue él quien abrió las fronteras de Eurasia a G. W. Bush y firmó con él y jefes de Estados occidentales la Declaración de Roma, que data de mayo de 2002. También la Federación Rusa experimentó la repugnante masacre de unas 400 personas, niños y familiares en la escuela de Beslan, Osecia del Norte, y se adhirió a la guerra duradera contra el terrorismo. Chechenia había demandado desde hacía años su independencia política, pero la respuesta militar rusa recordaba la represión en Hungría de 1956 y la entrada de los tanques soviéticos en Checoslovaquia, que tronchan la Primavera de Praga en 1968. Los imperios deben hacer memoria de su historia pasada; es lo que pretendo diseñar brevemente porque uno de esos grandes imperios puede acumular en el presente año nuevas masacres, que generarán nuevos odios.

\section{El foro de La Sorbona, París, 1990}

$[r$ ntre tanta literatura contemporánea de Perestroika quiero hacer una breve referencia al foro de La Sorbona, que tiene lugar en Paris, 1990. Luego de una macroencuesta realizada en ocho países del Este y Oeste europeo se reflexiona sobre sus resultados. El muro de Berlín ha caído y un año después se firma en Minsk la extinción de la URSS, del Pacto de Varsovia y del Comecon. Es normal que en este foro hablen con plena libertad los representantes de países satélites que por cinco décadas no habían disfrutado de ese derecho humano. También devuelven la acusación representantes de varios grupos sociales y socialistas Ilamados "socialtraidores" por Lenin en 1919. Un breve recuento que ayude a recordar y a aprender de la historia.
Para los participantes en el foro de La Sorbona había que aclarar un punto de terminología, donde los movimientos socialistas y socialdemócratas devuelven el bumerán que el comunismo soviético les había lanzado en 1919. Michel Rocard, Primer Ministro de Francia, trata de esclarecer este problema de terminología: "Los comunistas en el Oeste, y más todavía en el Este, quisieron apropiarse de la noción misma de socialismo, aunque lo que en el Oeste denominamos socialismo quiere decir socialdemocracia, sociedad pluralista, economía competitiva y diversificada, proyección social, y lo que se presentaba en el Este como socialismo significa para nosotros comunismo. Es pues importante establecer la veracidad de las palabras. Desde el golpe bol- 
chevique los principales dirigentes de la II Internacional, Leon Blum, Karl Kaustky y tantos otros dijeron lo esencial: que el voluntarismo de Lenin sólo podía conducir a una dictadura duradera sobre el proletariado, que sólo la democracia política permite conocer la voluntad popular; que la democracia no puede ser sólo un medio sino un fin. La oposición que de ahí derivó entre el comunismo y el socialismo fue irreductible en el fondo".

Es muy duro tener que reconocer que para nada sirve todo el arsenal atómico capaz de destruir el planeta, cuando buena parte de la humanidad ha perdido toda credibilidad en el primer país del "socialismo triunfante", que habían monopolizado el título de "socialismos reales". Es cierto que en el foro de Barcelona, 1988, en el foro de Moscú, 1989, en el foro de La Sorbona 1990, así como en la Mesa Redonda de historiadores soviéticos de 1988, se reconoce este fracaso histórico, tal como lo hace el último Secretario General del Partido Comunista de la URSS, Mijail Gorbachov. Sin embargo, la crítica más íntima e hiriente es la que proviene de los sacrificados por esa dictadura.

\section{El miedo a la política}

E $s$ un hecho patente las abiertas tensiones entre antiguos satélites de la URSS frente a la actual Federación Rusa y similares tensiones entre antiguas repúblicas del "patio trasero" de la URSS y la actual Rusia. Los testimonios que escuchamos en el foro de La Sorbona sobre el miedo a la política y la brusca gestación de los nacionalismos y de la consiguiente xenofobia nos ayudan a entender fenómenos similares que surgen desde el interior del Próximo y Medio Oriente ante la opresión de los respectivos imperios. A estos imperios, que tienen su nombre propio, les interesa contemplar el ocaso de imperio soviético. Una vez caído el muro de Berlín, los representantes de países satélites, Polonia, Hungría, Checoslovaquia, hablan con plena libertad sobre "el miedo a la política". En razón de la brevedad, traslado el testimonio de Bronislav Geremek, del equipo de Solidaridad.

"La política, tal y como se ha venido practicando durante decenios, es un monopolio del poder. El resultado ha sido el rechazo en bloque a la política, del fenómeno partido político. El partido político en nuestros países sigue siendo un fenómeno que se contempla con desconfianza y temor. Pero, puesto que pensamos que 1989 es la apertura de este nuevo siglo, ¿se abren acaso perspectivas nuevas que permitan articular la escena política? Acaso, al lado de los partidos deban aparecer movimientos como el mío, Solidaridad, que es una fuerza po- 
lítica centrada en torno a valores éticos y no a la lucha por el poder. Se puede columbrar ahí no sólo la desconfianza respecto al fenómeno de los partidos, sino acaso también uno de los signos de la evolución futura. Me atrevo a decir, aun pecando de optimista, que después de la felicidad que nos ha traído 1989, esa Europa, que busca hoy estructuras comunes, debería ver con realismo no sólo lo que preocupa a los europeos del Este, sino a todos los europeos, en general, algo que puede poner en peligro a toda Europa".

El problema a que se refieren los representantes de los países satélites son los movimientos centrífugos. Los nacionalismos insurgentes y la xenofobia, como una réplica natural al centralismo perpetuado. Estos sentimientos nacionalistas presentan, desde 1990, las tristes consecuencias confirmadas a lo largo de la última década. La primera faceta del pannacionalismo es que el Oeste se siente el anfitrión que recibe y adopta al Este con aires de superioridad. Sigue hablando B. Geremek: "Los temores que se sienten en Europa del Este se expresan de manera diferente, con cierto reflejo de autodefensa. Un reflejo nacional que se convierte en uno de los grandes peligros que acechan a toda Europa. En una palabra el peligro de nacionalismo. Este peligro se halla presente en todas nuestras sociedades posestalinistas del Este y del Oeste. Pero pienso en el porvenir de algunas actitudes de Europa occidental. Los comportamientos xenófobos y de miedo respecto del pobre europeo oriental que llama a la puerta del Occidente opulento. De esta forma, el temor define de manera nueva la vida en Europa oriental. La instauración de un mercado para millones de personas habituadas a la economía planificada -donde había una cierta estabilidad en la miseria - introduce la incertidumbre del cambio. Lo que se puede convertir en un obstáculo al cambio en Europa oriental es la apatía y el temor a la política".

Los países satélites no sólo se encuentran sin plan y sin mercado, sino que las nuevas políticas económicas de la Comunidad de Estados Independientes (CEl: miembros de la antigua Unión Soviética) los desvinculan del antiguo mercado planificado, mientras que el Mercado Común Europeo les levanta barreras protectoras para aquellos bienes exportables donde cuentan con ciertas ventajas comparativas. El temor al partido oficial y el ternor al opulento Occidente tienen su razón de ser. Uno de los temores emergentes era el nacionalismo resurgente de la unificación alemana. Tanto Willi Brandt como Gregory Gissi tratan de calmar estos miedos razonables: "La unificación alemana debe inscribirse en el proceso de la unidad europea y contribuir a la creación de lo que en palabra del presidente Milterand será una confederación europea. Para finalizar diré que este proceso de unidad está alumbrando una Alemania europea y no una 
Europa alemana. No necesitamos intereses de grandes potencias, ni un nacionalismo granalemán. Estoy convencido de que las ideas del socialismo democrático formarán una barrera en el camino del nacionalismo alemán. En todo momento nos esforzaremos para que los intereses alemanes se encuadren dentro de los intereses europeos de seguridad y de paz". Surge un problema que vuelve a amenazar al mundo quince años más tarde, es decir, en nuestros días.

El peligro es real, como lo deja entender el polaco Adam Michnik, que, luego de hacer su profesión de fe católica, invita a una confesión general del pecado de xenofobia. "Hay que preguntarse también si un orden autoritario, chovinista, fascistizante es posible en Europa Central. No hay que definir todas las luchas nacionales de Europa Central como chovinistas. Pero hay que comprender que las luchas nacionales tienen unas consecuencias muy ambiguas. El resultado es la libertad, pero también la xenofobia. Me he puesto algo nervioso al escuchar a los intelectuales. Yo creía que Willi Brandt, el líder de la II Internacional, se manifestaría contra las manifestaciones antipolacas de Leipzig, contra las consignas de "¡Polacos, fuera!", escritas en las paredes de las ciudades alemanas, pero no lo ha hecho. Hay que terminar con estas prácticas. Me pronuncio contra todas las acciones antigermánicas, antilituanas, antiucranianas en mi patria. Estoy seguro de que este movimiento de xenofobia, de odio nacional, sería una catástrofe para toda Europa Occidental. Este es el problema más dramático y complicado de toda la Europa contemporánea. En este contexto podemos declarar abiertamente que somos culpables $y$ debemos decir algo contra nuestro corazón y no contra el corazón de nuestros vecinos".

Con Jorge Semprún, ministro de Cultura del gobierno socialista español, se introduce como nuevo elemento el factor religioso, objeto de respeto. En el foro de Moscú, Yuri Kariakin, diputado y defensor de la Perestoika, afirmó: "Hay que fusilar la religión, dijimos nosotros, y fusilamos la moral, y el socialismo fue inhumano, por no decir antihumano y ahora cosechamos los frutos de esas ideas inicialmente tan nobles". Uno de los fenómenos que fortalecía la resistencia creciente frente a los partidos comunistas, oficialmente ateos $y$ perseguidores de cualquier confesión religiosa, ha sido el factor religioso. El caso más notable era Polonia; junto con el grito "¡no hay pan sin libertad!", demandaban que la televisión transmitiera la misa dominical porque el $93 \%$ de la población era católica. Con el desmembramiento de la URSS el factor religioso refuerza el proceso nacionalista en todas las esquinas del Este europeo. Quien fuera ministro de Asuntos Exteriores de la URSS, Edward Shevarnadze, se hace bautizar en la Iglesia Ortodoxa con el nombre de Gregory y fue por un tiempo presidente de la 
república de Georgia. El factor religioso, como gestador de los más fuertes nacionalismos, no es monopolio de los otrora socialismos reales; baste recordar los conflictos del Próximo y Medio Oriente. Una vez más, el dogmatismo central generó una nueva fuerza de desintegración, y repetimos la historia en el tercer milenio.

"Mi tercera observación", dice Jorge Semprún, "concierne al peligro de los extremismos nacionalistas y religiosos. Empecemos por el principio. Digamos que la extraordinaria necesidad de afirmación de la identidad nacional es uno de los componentes iniciales de la resistencia y posteriormente de la afirmación de la democracia. El zarismo fue la prisión del pueblo; el estalinismo lo multiplicó no sé por qué factor. Pero, ¿dónde establecer la frontera entre la necesidad absolutamente ineludible, imperiosa y democrática de la afirmación de la identidad nacional y el peligro nacionalista? Se trata de un problema que hay que resolver en la práctica, en el pragmatismo de la acción. Lo mismo diré respecto de la afirmación de la fe, sea católica o protestante en todos los países en que ha jugado un papel. Polonia es un caso particular de lo que digo. Tenemos en Occidente una tradición laica $y$ crítica que es justa y necesaria, que se remite a los valores universales, pero hay que comprender el papel que la Iglesia ha tenido en la conservación de la identidad nacional. Por ello, atención cuando se manipulan de manera desconsiderada los peligros extremistas del nacionalismo. Atención, porque corremos el riesgo de separarnos de una parte importante de las fuerzas democráticas de Europa de Este". ("Sistemas económicos comparados". Cuadernos de cátedra, 2001; pp. 150-158)

"Con el golpe de Estado de 1991 se pone fin a la Unión Soviética en un asombroso clima de tranquilidad y orden. La Unión Soviética había dejado de existir como sujeto de derecho internacional público y como realidad geopolitica. El 25 de diciembre, el último Presidente de la Unión Soviética presentó su renuncia; se arrió la bandera de la Unión Soviética y se izó la bandera tricolor de la Federación Rusa. En el término de pocas semanas la comunidad de naciones reconoció a Rusia y a la mayoría de los Estados sucesores de la Unión Soviética como naciones, como nuevos sujetos del derecho de los pueblos o como derecho habientes respectivamente".

Conviene recordar que el decreto de Minsk se firmó con el consentimiento de la república rusa, como un modo de liberarse de la pesada carga de las otras repúblicas de la Unión. El programa de M. Gorbachov de mantener cierta unidad entre las quince repúblicas a modo de Comunidad de Estados Independientes (CEI) no prosperó, por oposición de Boris Yeltsin. Algunas de las catorce repúblicas independientes siguen viviendo un proceso de involución hacia mode- 
los de cuño estalinista, de partido único aunque con simulacros de elecciones predeterminadas. Otras se mueven en esa cuerda floja de mayor o menor cercanía al Kremlin de Moscú. El problema más serio es la transición de la Federación Rusa desde la contracción hasta el caos económico bajo la égida de Boris Yeltsin y la aparición de los "nuevos zares" luego de la "privatización desvergonzada" de las grandes empresa y unidades públicas. Proceso que ha quedado bien descrito por el historiador luri Afasaniev, en su obra Mi Rusia fatal. La denuncia de un historiador comprometido. (E. Anaya \& Mario Muchnik, Barcelona 1994) A Boris Yeltsin le sucede Vladimir Putin.

\section{El pacto Moscú-Washington}

Diez meses después del 11 de septiembre, G. W. Bush visita cuatro países de Europa, Alemania, Rusia, Francia e Italia para presentar su nueva biblia de bolsillo sobre el eje del mal. Sin duda la parada más importante es la Rusia que hereda V. Putin en una situación económica caótica. En espera de ayudas necesarias, Putin firma una serie de "alianzas flexibles" con G. W. Bush, de lo cual ahora parece estar arrepentido. El primer acuerdo, cuyo borrador ya estaba pactado, es la reducción de arsenales nucleares de ambas potencias a un nivel máximo de 2.200 ojivas de aquí a 2012. Un descenso significativo de las 6.000 hoy existentes, en mayo de 2002. Norteamérica anuncia que almacenará sin desmantelar las ojivas retiradas, mientras que Rusia guarda la posibilidad de instalar múltiples cabezas en los misiles conservados. Para Rusia este pacto es ventajoso, porque no cuenta con los recursos financieros para mantener su actual arsenal y porque espera nuevas ayudas económicas luego de este acuerdo que "pone fin a la guerra fría". La víspera de la llegada de Bush a Moscú Putin dijo que Rusia y los Estados Unidos han logrado "desde hace un año crear un clima de mutua confianza y comprensión, demostrando que nuestros países no son adversarios". ("Vladimir Putin consacre son raprochement avec les États Unis". Le Monde, 23 de mayo de 2002)

Se iniciaría así la era de las concesiones económicas a cambio de la nueva alianza política. La "guerra contra el terrorismo" y los recursos petrolíferos absorben la atención de ambos mandatarios en los países de Asia Central y del Cáucaso, sacudidos por múltiples conflictos nacionalistas y terreno abierto a toda clase de tráficos. Estados Unidos y Rusia actuarán "conjuntamente" para resolver muchos conflictos regionales, entre otros el caso de Chechenia, y 
para favorecer la explotación de los recursos energéticos del Caspio. Esto significaba dar un derecho de inspección a los Estados Unidos sobre una amplia zona que había sido coto cerrado de Rusia. En la declaración conjunta sobre "la cooperación contra el terrorismo" ambos mandatarios juzgan que "la soberanía, la estabilidad durable, la prosperidad y el desarrollo democrático futuro de los Estados de Asia Central sirven los intereses de Estados Unidos y Rusia". Se hace mención especial de Georgia, donde han surgido elementos terroristas $y$ donde ya han comenzado a llegar instructores norteamericanos para adiestrar a las fuerzas nacionales.

Se suman dos razones. Los conflictos independentistas en toda la región del Cáucaso y la imprevisibilidad de Asia Central amenaza la lucha mundial contra el terrorismo y la seguridad norteamericana, porque si estas regiones se hunden en el caos $y$ en conflictos violentos contra civiles pueden convertirse en terreno propicio para los extremistas y para la red $\mathrm{Al}$ Qaeda. Además en esta región están en juego los recursos petroleros. Ambos mandatarios han firmado un pacto energético "uniendo sus esfuerzos para desarrollar los vastos recursos energéticos de Rusia y de la región del Caspio". La cooperación energética ruso-norteamericana en Rusia y en las zonas fronterizas a Rusia "refuerzan la soberanía, la cooperación y la in- tegración en la economía mundial de todos los Estados participantes" ("Les États Unis et la Russie scellent une nouvelle alliance". Le Monde, 25 de mayo de 2002)

V. Putin abre las puertas a la "cooperación" norteamericana. La inversión se extenderá también a la modernización de la infraestructura portuaria y del transporte del gas y petróleo. Dos compañías norteamericanas, Chevron Texaco y Exxon Mobil, han firmado contratos para transportar el crudo a través del mar Caspio y para la modernización de las plataformas marinas de extracción del crudo. Otras compañías invertirán en la prolongación del oleoducto que atraviesa las zonas conflictivas de Asia Central. La geopolítica se une a la geoeconomía para lograr un abastecimiento más estable para Europa y también Estados Unidos.

Putin tiene otras razones para firmar estas alianzas flexibles. También son puntos de agenda otros problemas económicos. Rusia sostiene una deuda externa de $\$ 138.000$ millones. Putin logró que Gerhard Schröder redujera la deuda rusa a Alemania de 6.000 millones de euros a sólo 500 millones. El FMI se ha resistido durante años a hacer nuevos préstamos a Rusia mientras el gobierno no tomara medidas más drásticas para írenar la salida de esos fondos a cuentas externas de los "nuevos zares" o personas allegadas al ex presidente Boris Yeltsin. Putin espera que los 
nuevos acuerdos político-económicos puedan abrir la válvula de nuevos créditos. Esto significa que Putin debe hacer un gran esfuerzo por afianzar su economía, en estado bastante caólico luego del ascenso de los nuevos oligarcas en la era Yeltsin, así como una modernización política asentada en los principios democráticos del respeto de los derechos humanos, de las minorías étnicas, de la libertad de prensa, de la separación de poderes y de la economía de mercado. Todo esto le abriría las puertas para que Estados Unidos apoyara el ingreso de Rusia en la Organización Mundial del Comercio. Ahora Rusia forma parte del Consejo OTANRusia, firmado en Roma el 27 de mayo de 2002. Bush logró su objetivo principal de englobar a Rusia y Asia Central en el pacto antiterrorista y Putin espera poder obtener amplias ventajas económicas, el problema mayor de la "Gran Madre Rusia". ("Vladimir Putin consacre son raprochement avec les Etats Unis". Le Monde, 23 de mayo de 2002. "Bush y Putin refuerzan su alianza con un gran acuerdo de venta de petróleo". El País, 25 de mayo de 2002. "La inseguridad: el regulador de la economía mundial". Realidad, No 88, 2002, pp. 433-436)

La "Declaración de Roma" se abre ante un nuevo horizonte: "Vivimos en un mundo nuevo, donde nuevas amenazas y desafíos exigen respuestas cada vez más unidas.
Por esta razón los Estados miembros de la OTAN y la Federación de Rusia abrimos un nuevo capítulo en nuestras relaciones". Siguen los numerales que establecen los acuerdos de la alianza. Se trata de participantes iguales en los temas de interés común. Se aplicará el "principio del consenso". Será presidido por el Secretario General de la OTAN. Se reunirá dos veces al año al nivel de ministros de asuntos exteriores o ministros de defensa y una vez al mes al nivel de embajadores.

A la hora de los brindis los jefes de Estado levantaron su copa y recitaron nuevos salmos: "El terrorismo tiene unos medios excepcionales que requieren una respuesta excepcional", declaró Jacques Chirac. "El pueblo británico ya no teme al ruso, pero los dos tememos al terrorismo", señaló Tony Blair. "No pueden vencernos, no tienen ninguna oportunidad", espetó Berlusconi a los terroristas. "Los valores no se defienden solos. No debemos esperar sentados a ser agredidos", añadió J. M. Aznar. La mayoría de líderes destacaron el protagonismo de Rusia, de Putin en particular, que, aparte de comprometerse a la defensa de la democracia y la libertad, tendrá que enfrentar algunos recelos internos de la clase militar. Puesto que Rusia se une a este esfuerzo europeo, Putin exigió un respeto recíproco: "No podemos pensar Rusia fuera de Europa". (Ibídem, pp. 439-440) 


\section{7. "La guerra sin fin", un error}

$\mathrm{E}^{3}$ ste título es una combinación de dos editoriales de Le Monde que sirve a presentar la siguiente tesis: "combatir el terrorismo con la política y no con la guerra". El 3 de septiembre de 2004 un grupo de terroristas chechenos toma como rehenes a un millar de niños, familiares y profesores de la escuela de Beslan, en Osetia del Norte, Rusia, y masacran a unas cuatrocientas víctimas inocentes. "La masacre del 3 de septiembre (3S) es un cruel golpe para los rusos como el $11 \mathrm{~S}$ lo fue para los norteamericanos", dice uno de los editoriales. "Cruel es una palabra débil: la lectura del testimonio de la subdirectora de la escuela de Beslan no deja duda alguna sobre la barbarie de quienes en su asesina locura deciden esta toma de rehenes, cuyas consecuencias se vieron agravadas por la incuria y la brutalidad de los agentes rusos. Ninguna causa puede justificar jamás tales actos". Conviene insistir en el lado cruel del terrorismo internacional, que es algo real. ("El error". Le Monde, 10 de septiembre de 2004)

Esta sería una de las caras de la medalla, pero conviene mirar el reverso para abarcar la historia de todas las consecuencias. En este entorno, tanto G. W. Bush como V. Putin anuncian un programa de guerra sin fin. "Todo sucede como si, en realidad, tanto el uno como el otro se concentrasen en limitar su gestión de la situación internacio- nal en una sola consigna: la lucha del terrorismo internacional. Del Cáucaso a Manhattan, pasando por los extrarradios de las ciudades europeas, un solo enemigo, una sola potencia maléfica, el terrorismo internacional". No es de extrañar que $V$. Putin haya manifestado sus preferencias por G. W. Bush en la campaña electoral, porque ambos enarbolan la misma política de lucha contra el terrorismo mundial para ganar apoyos: uno, el del partido "Rusia Unida"; el otro, el del electorado más guerrerista.

A ambos se dirige el editorial de Le Monde: "Su guerra sin fin". "No sería la victoria de nuestros ideales democráticos y humanistas, sino al contrario la del terrorismo que pretende combatir, de un terrorismo que proclama "la guerra a la política", la desea y la llama tanto para atentar contra civiles como por la barbarie en su forma de actuar. Frente a este adversario, si no queremos caer en la trampa que nos tiende un día tras otro y parecernos a él en el odio y la violencia, no hay mas que un antídoto, una sola arma decisiva, la política. No permitir que la guerra reemplace a la política".

"La toma de rehenes en la escuela de Beslan es algo abyecto, pero los chechenos son víctimas de una guerra colonial, donde, por lo que toca a la barbarie, las tropas rusas no quedan atrás. Los atentados de kamikazes en los autobuses israe- 
litas son horrendos, pero el pueblo palestino es víctima de una ocupación que le deniega el derecho legítimo a un Estado. El degollamiento de rehenes suscita un horror que provoca su misma filmación, pero Irak vive bajo la ocupación militar extranjera que, pese a haber puesto fin a una dictadura, sigue generando el caos por falta de previsión y cordura. El terrorismo, tan innoble como es, tiene un semillero bien abonado. Nos toca alimentarlo o desecarlo. La guerra sin fin es elegir un terrorismo para siempre. Esta guerra sin fin que no da la independencia a Chechenia, ni un Estado a los palestinos, ni una verdadera soberanía a los iraquíes, es una guerra sin vencedor. Una guerra que nunca acabará". (Le Monde, 10 de septiembre de 2004)

"Tres semanas después de la carnicería de Beslan, V. Putin se decide a poner en obra el fortalecimiento del poder central de los ministerios de Seguridad, Defensa e Interior. Más de cuarenta proyectos de ley se presentan al Parlamento para luchar contra el terrorismo internacional. La Duma, dominada por el partido presidencial, Rusia Unida, ha adoptado el pasado miércoles una resolución que pide la consolidación de todas las estructuras de poder. Las medidas programadas organizan el mayor control de los extranjeros, limitan la circulación de personas $y$ prevén una censura de los medios de comunicación en caso de crisis. Se constituye una especie de gobierno paralelo en todo el Cáucaso del Norte, desestabilizado por la guerra en Chechenia". ("El Kremlin confiere todos los poderes a los servicios de seguridad". Le Monde, 23 de septiembre de 2004) Como ha dicho el último de los dirigentes soviéticos, Mijail Gorbachov: "Un Gobierno no arregla sus problemas limitando los derechos de la ciudadanía".

Al interior de Rusia se están llevando a cabo reformas de cuño antiterrorista. Putin anunció el 17 de noviembre que Rusia iba a contar pronto con nuevos sistemas de armas nucleares, que "no existen ni existirán en los próximos años en otras potencias nucleares. Seguimos con las investigaciones $y$ ensayos de sistemas nucleares más modernos. Estoy seguro de que en los próximos años serán parte de nuestro equipo nuclear". De acuerdo a los expertos parece que se trata de misiles de 10.000 kilómetros de alcance. "Bastaría con que descuidáramos nuestra atención a estos componentes de nuestra defensa, que forman parte de nuestro escudo de misiles nucleares, para que nos encontremos confrontados a otras amenazas". Sin embargo Putin no especificó cuáles eran esas amena-

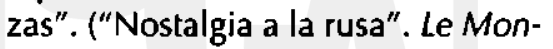
de, 18 de noviembre de 2004)

Resulta que los dos grandes imperios atómicos se siguen celando el uno al otro y cada cual toma sus medidas en clave mayor. Dos preguntas: ¿cuál es la gran inseguridad? $Y$ la gran inseguridad, ise combate con la política o con la amenaza de 
guerra? Tanto Colin Powell, Secretario de Estado, como el mismo G. W. Bush, han pedido una explicación de estas medidas. S. Laurov respondió: "Estas medidas se basarán en la Constitución de nuestro país, y continuaremos con la defensa de nuestros intereses legítimos a través de un diálogo amigable, la cooperación y la ayuda, más que por la confrontación. Se trata de reforzar la unidad del país y de nuestro pueblo para luchar contra el terrorismo y garantizar una existencia segura a nuestros ciudadanos en libertad y democracia". Por su parte, Putin acusó a Occidente por el doble rasero en cuestiones de terrorismo, persiguiendo por un lado a los fundamentalistas islámicos en Afganistán e Irak, mientras "dan refugio a los terroristas" chechenos que piden la independencia de Rusia. Dar cobijo y apoyo a terroristas, a sus cómplices y promotores les sirve de justificación y les anima a cometer crímenes", aseguró el presidente ruso. "Putin considera la política estadounidense dictatorial". El País, 4 de diciembre de 2004)

No deja de ser bastante cínica la postura seudomoral del presidente Bush cuando su ministro de Justicia John Ashcroft, luego del 11 septiembre edita el Acta Patriótica; una serie de leyes que coartan derechos civiles fundamentales, que fueron criticadas -entre otros- en la carta abierta de Norman Birbaum, profesor emérito de Georgetown: "Los preparativos del Gobierno Bush para la guerra incluyen restriccio- nes draconianas para los derechos de los residentes o visitantes árabes o musulmanes en Estados Unidos. Quienes respaldan al presidente han organizado una campaña de difamación e intimidación contra aquellos ciudadanos que manifiestan su disensión. Grotescamente, el plan milenarista del Gobierno Bush para democratizar a Oriente Próximo nunca se ha debatido en el Congreso ni en la nación. El presidente Bush sostiene que nuestro país tiene derecho a eliminar enemigos en potencia mediante ataques preventivos. La proclamación del derecho del ataque preventivo por parte de una nación contra otra es un asalto definitivo contra la dolorosamente construida estructura del derecho Internacional. Es una invitación a que otros países sigan su ejemplo. Estados Unidos ya ha transgredido el derecho internacional con el trato dado a los prisioneros que ha hecho en Afganistán o que han sido capturados por los gobiernos aliados en otras partes. Aceptan ustedes con pasmosa tranquilidad la afirmación de que el régimen iraquí y sus armas de destrucción masiva representan una clara amenaza para la seguridad mundial. Repiten algo que no es mas que una ficción de la Casa Blanca: que Irak respalda a Al Qaeda. No hay prueba convincente de ninguno de los dos argumentos. Tratan ustedes la obsesión del presidente Bush con Irak como algo racional". (El País, 9 de febrero de 2003) 
- I pasado 15 de febrero, Rusia amenaza con retirarse del tratado de eliminación de ojivas nucleares de alcance intermedio y corto (Intermediate Range Nuclear Forces, FNI) firmado en 1987, si Estados Unidos no renuncia a su "escudo antimisil" en Europa Central. "Lo que Norteamérica hace en este momento - crear una tercera zona de ampliación para la defensa antimisiles en Europa - es totalmente inexplicable", declaró el general Yuri Baluesvsky, jefe de estado mayor de las fuerzas armadas rusas. Aunque oficialmente Estados Unidos haya tratado de apaciguar los ánimos, sin embargo todo esto ha provocado tensiones con Washington. El jefe supremo de las fuerzas aliadas de la OTAN en Europa, el general John Craddock, ha declarado que el proyecto de instalar un escudo antimisil en las fronteras rusas es transparente y no amenaza a Rusia. "Creo que las intenciones de Estados Unidos han sido manifestadas con toda claridad, a saber la instalación de nuevas capacidades de defensa contra un ataque de misiles provenientes de estados sin ley, dijo en Varsovia, una de las naciones donde se han instalado.

El representante del Departamento de Estado, Sean McCormack afirmó: "Hemos propuesto a Rusia cooperar en la defensa civil porque nosotros creemos que enfrentamos amenazas del Medio Oriente, igual que otras zonas". Un alto responsable del Pentágono manifestó que Estados Unidos se resistirían a la tentativa de retiro de Rusia del tratado FNI, porque esto tendría serias consecuencias para los aliados de Washington en Europa". Estados Unidos tienen instalada una red de satélites de alerta y de radares detectores, así como interceptores de misiles en Alaska y en California, y desean complementar su sistema de defensa para contener eventuales ataques de Irán o de Corea del Norte ampliando su escudo en Europa. ("Pulso entre Moscú y Washington en torno al escudo antimisil americano". Le Monde, 16 de febrero de 2007)

Una vez más, el Gobierno de Estados Unidos asienta su política en la teoría de la guerra preventiva. Como hay que justificar los enormes presupuestos del Pentágono y las escandalosas partidas en defensa interna, necesariamente hay que convencer a los miembros del Consejo de Seguridad y a la Unión Europea que Irán es una seria amenaza con sus proyectos de enriquecimiento de uranio, que, de acuerdo a los expertos, sólo pueden actualmente aplicarse a producción civil de electricidad. La Administración Bush, que se ha negado a ratificar los estatutos de la Corte Penal Internacional, se ha especializado en el arte de mentir y engañar, sobre todo a sus propios 
conciudadanos. Igual que en los meses de enero y febrero de 2003, volvemos a escuchar similares amenazas contra el Gobierno de Irán. Lo que está consiguiendo la Administración Bush, con esta política preventiva, es que todos los países que puedan entren por la puerta trasera en el club nuclear. Necesitamos escuchar a Irán.

"Vladimir Putin quiere ofrecer una alternativa a la "política unilateral' de Washington", afirma el diario Le Monde. Putin hace un recorrido por repúblicas cercanas a Washington, Arabia Saudita, Qatar y Jordania, acompañado de representantes de la gran industria rusa, así como de las empresas encargadas de la venta de armas. Propone a estos gobiernos una cooperación económica más estrecha y una alternativa a la "política unilateral" de Washington. "Nosotros nos esforzamos por crear un orden mundial más justo, fundado en los principios de la igualdad", dirá Vladislav Sourkov, el portavoz de Krenlim. Este "new deal" consiste en mostrar que Rusia, igual que la URSS en su tiempo, es capaz de hacer frente a la política norteamericana en diversos aspectos. Se ha aprovechado la oportunidad en Qatar y en Jordania para lanzar la idea de una conferencia regional sobre el conflicto israelo-palestino, y se pro- curará que Irán y Siria participen. Dado el debilitamiento de la posición norteamericana en el Medio Oriente, Rusia reivindica su papel de árbitro y mediador.

Con relación al tema nuclear de Irán, Rusia tratará de hacer lo posible para impedir la adopción de nuevas medidas de parte de Naciones Unidas. Rusia tratará de defender sus propios intereses en Irán, país a quien ha apoyado con sistemas de armamentos, misiles antiaéreos de corto alcance, y con ayudas para el desarrollo del "nuclear civil". Rusia trata de hacer más bien un papel de obstrucción en esa zona, en contra de la posición de Estados Unidos y Europa, ha mostrado su deseo de que esas naciones pongan fin a las sanciones contra palestina. V. Putin ha declarado el pasado martes 13 de febrero, al presidente de la autoridad palestina, Madmoud Abbas, que "él espera que las sanciones económicas impuestas por los Estados Unidos y la Unión Europea al gobierno palestino sean muy pronto levantadas, luego del acuerdo firmado en La Meca, el 8 de febrero, que permitan dar los siguientes pasos hacia el arreglo total". También ha aconsejado a su homólogo palestino que "sería muy útil" liberar al caporal israelí para que Gaza sea liberada. (Le Monde, 14 de febrero de 2007)

\section{Irán en el centro de Munich}

I negociador iraní Ali Lariya-
ni defendió el derecho legíti-
mo de Irán a hacer uso de la energía nuclear civil en tanto que Estado parte del Tratado de No Proliferación Nuclear, un derecho que 
los negociadores iraníes quieren que quede reflejado en el texto de cualquier acuerdo. Insistió en que la doctrina de la Defensa de Irán es "únicamente defensiva" y que Teherán no tiene la menor intención de reconvertir su programa nuclear con fines militares. "Lariyani denunció que se quiera condenar a Irán por un crimen que no ha cometido y que la comunidad internacional, liderada por algunos países, actúe en función de apreciaciones y no de hechos. Recordó que todas las instalaciones nucleares iraníes están abiertas a los inspectores del Organismo Internacional de Energía Atómica, lo que demuestra que están dispuestos a cooperar"

A la pregunta de si Irán aceptará suspender el programa de enriquecimiento de uranio, como exige la comunidad internacional para el establecimiento de negociaciones, Lariyani reiteró que "una solución justa debe conciliar los intereses de las dos partes, un objetivo que a su juicio es posible. Siempre y cuando se tenga una visión realista de las cosas" (Deutsche Welle, 24 de febrero de 2007) El embajador adjunto iraní ante Naciones Unidas, Mehdí Danesh Yazdi, asegura que su país cumple sus obligaciones de acuerdo a los tratados internacionales. "Irán ha acusado a EE.UU., Reino Unido e Israel de fabricar hechos y realidades sobre su programa nuclear en una campaña masiva que esconde motivaciones políticas y ha afirmado que está acatando todas sus obligaciones bajo los tratados internacionales". Durante la re- unión, los embajadores de EE.UU., Reino Unido e Israel denunciaron a Irán públicamente por no cumplir con las resoluciones de la ONU en materia de no proliferación nuclear, ante su negativas de suspender sus actividades de enriquecimiento de uranio.

El diplomático iraní respondió que "es lamentable que una campaña mal intencionada con motivaciones políticas esté intentando distorsionar $y$ fabricar hechos $y$ realidades" sobre su "programa nuclear pacífico. Nadie en el mundo de hoy puede aceptar la lógica irracional de que está bien para aquellos que tienen armas nucleares $y$ amenazan con sus arsenales y políticas agresivas, mientras que luego lanzan aullidos sobre los programas nucleares pacíficos". Yazdi ha remarcado que la no-proliferación es un asunto de suma importancia para la paz mundial, y que la forma más efectiva de prevenir que caigan en manos de actores no estatales es la eliminación total de estas armas de destrucción masiva. "Irán cree que la comunidad internacional debe luchar para asegurar que pesadillas creadas por EE.UU. contra la población de Hiroshima y Nagasaki nunca vuelvan a ocurrir. Por lo tanto, la única garantía absoluta es eliminar las armas nucleares", afirmó.

Consideró que la cuestión de la no-proliferación nuclear está vinculada estrechamente con el desarme, algo que no se contempla en las resoluciones del Consejo de Seguridad, que fueron motivo de debate de la reunión. "Los esfuerzos hacia 
5 la no-proliferación deben ir en paralelo con las iniciativas de desarme", puntualizó. Dijo que Irán ha cumplido con las resoluciones de la ONU en materia de no-proliferación y que, además, ha establecido leyes y regulaciones nacionales para combatir el tráfico ilícito de estas armas y municiones. Yazdi aseveró que "su país no aceptará que estas resoluciones se interpreten o implementen contraviniendo los derechos y obligaciones de los países a los instrumentos internacionales, como el Tratado de NoProliferación (NTP) de Armas Nucleares $y$ el estatuto internacional del Organismo Internacional de la Energía Atómica. "Irán considera que desarrollar energía nuclear para fines pacíficos es un derecho inalienable bajo el NTP". El gobierno de Teherán ha permitido las inspecciones de la OIEA, que han sido las más duras a las que ha sometido a un país miembro de la ONU. "Todos los informes de la OIEA desde 2003 han indicado la naturaleza pacífica del programa nuclear iraní y la agencia ha reiterado que no ha habido ningún desvío de material para fabricar armas nucleares $u$ otros explosivos atómicos", concluyo. ("Irán acusa a EE.UU. y Reino
Unido de fabricar "pruebas falsas" sobre su programa nuclear". El País, 24 de febrero de 2007.)

Todavía nos queda la esperanza de que "los europeos puedan atemperar a los Estados Unidos". (Le Monde, 21 de febrero de 2007) Este tortuoso recorrido de la gestación de una nueva guerra fría entre un imperio del pasado y otros imperios del pasado $y$ del presente nos ayuda a entender que los imperios son los verdaderos multiplicadores de la inseguridad. Los imperios no conocen otra medida para gestar la seguridad que la "guerra sin fin". Su propia inseguridad les convierte en señores de la guerra, que tratan de disfrazarla con títulos falaces: $E I$ choque de civilizaciones, de Samuel $P$. Huntington. Después nos enteramos de que $S$. Huntington fue, por largos años, consejero del Pentágono; "su teoría estaría buscando justificar gastos complementarios en defensa nacional". Las civilizaciones no chocan, dialogan y se enriquecen con nuevos principios. Quienes chocan son los imperios, como ha tratado de mostrarlo el presente comentario, dejando en la vía muerta el logro de los objetivos del milenio. 